\title{
Peer assessment in a test-dominated setting: empowering, boring or facilitating examination preparation?
}

\author{
Darren Bryant and David Carless \\ Faculty of Education, University of Hong Kong \\ E-mail: dcarless@hku.hk
}

\begin{abstract}
The literature suggests that peer assessment contributes to the development of student learning and promotes ownership of assessment processes. These claims emerge from research conducted primarily in Western contexts. This exploratory paper reports on the perspectives that a class of Hong Kong primary school students and their teachers have on their engagement with peer assessment. It draws on data collected through extensive interviews and classroom observations from a two-year case study. The findings indicate that student perceptions about the usefulness of peer assessment follow from their perspectives on quality of peer feedback, peer language proficiency and the novelty or repetitiveness of its processes. Teachers and students also viewed peer assessment as assuming a wider role in preparing for examinations and future secondary schooling. A key implication is that assessment practices are deeply cultural and in test-dominated settings peer assessment may have most potential when explicit links are drawn with preparation for summative assessment.
\end{abstract}

Key Words: Peer assessment, formative assessment, examinations, English language teaching, primary school, case study

\subsection{Introduction}

The potential of formative assessment to support improved student achievement has been a major focus of research in Anglophone countries over the last decade (e.g. Black \& Wiliam, 1998; Gardner, 2006; McMillan, 2007), has attracted 
much interest internationally (OECD, 2005) and is increasingly on the policy agenda in the Asia-Pacific region (Kennedy \& Lee, 2008). In Hong Kong, as part of wideranging reforms intended to promote life-long learning, educational authorities have articulated the need to develop a new culture of assessment less reliant on traditional one-off examinations. Included in this agenda are calls for more peer and selfassessment to promote reflective thinking, self-improvement and independent learning (Curriculum Development Council, 2001, 2004). The successful implementation of formative assessment has, however, been more common in Anglophone settings (e.g. Black, Harrison, Lee, Marshall \& Wiliam, 2003) than in Asian ones, as the associated pedagogy is rooted in constructivist learning principles originating in the West. Given that these practices differ markedly from the traditional model of education practiced in Hong Kong (Walker, 2007), questions arise regarding the extent to which formative assessment may be successfully implemented without adaptation to local contexts (Kennedy, Chan, Fok \& Yu, 2008). Exacerbating these challenges is a history of reform efforts in Hong Kong marked by rhetorical or symbolic purposes, with a concomitant lack of commitment to addressing the challenges of supporting changes at the school frontline (Morris \& Scott, 2003).

The implementation of formative approaches to assessment faces multiple challenges that have been well-rehearsed in the international literature (e.g. Tierney, 2006) and with respect to Hong Kong (e.g. Carless, 2005; Kennedy et al., 2008). A key challenge relevant to this paper is the dominance of summative assessment. Hong Kong teachers seem to view formative approaches, such as peer assessment, as a Western innovation not necessarily practical in a Chinese setting (Carless, 2005), whereas summative assessment is deeply rooted in the educational culture and generally understood and valued by society at large (Biggs, 1996; Poon \& Wong, 2008). A reverence for examination-oriented education in Hong Kong is combined with predominantly teacher-centred instructional styles focused on textbook coverage and heavy doses of homework supplemented by drill and practice tests (Adamson \& Morris, 1998; Kennedy et al., 2008). Indeed, the dominance of summative assessment has impeded previous attempts at assessment reform (Morris, 2000).

Given the challenges of implementing assessment change, Kennedy et al. (2008) have warned against assumptions that the promotion of formative assessment somehow solves problems inherent in summative assessment, and have suggested a need to focus on broader cultural contexts. They also point to a dearth of research 
related to formative assessment in Asian classrooms. In view of these gaps in the literature, this exploratory paper aims to cast light on the implementation of peer assessment by analyzing data from a case study involving two teachers of English as a second language co-teaching in a primary school classroom, The value of the paper lies in probing the potential and challenges of implementing peer assessment in a culture where examinations have always dominated.

The remainder of the paper is organised as follows. First, we review research on the potential benefit for students in engaging in peer assessment, emphasizing relevant cultural aspects. Then, we describe the research method. The findings analyze the perspectives of students and teachers as they engage with peer assessment; and discuss possibilities and challenges occurring in its implementation. Finally, we suggest areas of potential to facilitate the implementation of peer assessment and outline some avenues for further research.

\subsection{Literature review: framework for analyzing peer assessment}

We review relevant literature in two sub-sections in order to develop a framework for the analysis of the implementation of peer assessment. The first part looks at the rationale, potential and challenges of peer assessment from a Western perspective. The second takes into account educational and cultural factors in implementing peer assessment in the Hong Kong setting.

\subsection{Potential and challenges of peer assessment}

For the purposes of this paper, peer assessment refers to students using criteria to make judgments about the work of their peers and provide comments and/or grades as part of this process. Self-assessment involves students in applying criteria to their own work, and making judgements about the extent to which they have met these criteria. While this paper focuses on peer assessment, occasional references to peer and self-assessment together are used to acknowledge the potential synergy between them or to indicate implications of the findings for both forms of assessment.

The theoretical basis for peer assessment is that it enables students to take an active role in the management of their own learning. It is an element of self-regulated learning by which students monitor their work using feedback from external sources such as peers' contributions in collaborative groups (Butler \& Winne, 1995). Involving students in the assessment process is widely recognized as essential to 
effective self-regulation by enabling students to uncover missteps and develop strategies to redress them (Bransford, Brown \& Cocking, 2000). However, the development of peer assessment skills is challenging. The process requires ongoing and repeated practice for students to become competent assessors (Oscarson, 1997; Sadler, 1989). Engagement in peer assessment over the long-term requires sustaining both students' involvement in high quality tasks as well as their "passionate positive feelings about these tasks” (Munns \& Woodward, 2006, p. 197). Thus engagement in peer assessment aims to impact positively on students' cognitive development and affective enjoyment of learning (Fredricks, Blumenfeld \& Paris, 2004).

One of the intentions behind peer assessment is that it can lead students to consider more carefully the same elements of their own work (Black et al., 2003). As students learn more comfortably when comparing their work and discussing it with peers than with teachers, the likelihood of expressing opinions, asking questions and debating options increases (Deakin-Crick, Sebba, Harlen, Yu \& Lawson, 2005). On the other hand, a small-scale qualitative study with New Zealand secondary school students found that students believe feedback from peers to be unhelpful because students are perceived as lacking appropriate expertise, friends would comment too positively and it is what the teacher says that counts (Peterson \& Irving, 2008).

When students are working collaboratively in assessment, distinctions between formative and summative assessment are sometimes blurred because feedback on performance is immediate and learners do not have to wait to get feedback on their work (Deakin-Crick et al., 2005). Importantly, such practices have potential for improving students' subsequent performance in summative assessments. For example, McDonald and Boud (2003) found that secondary school students who were trained in self-assessment scored significantly higher on public examinations in various subjects than did control groups which did not receive such training. Student involvement in assessment also seeks to prepare students for life-long learning (Deakin-Crick et al., 2005).

In contexts where excessive testing negatively impacts on motivation by reinforcing student failure and lack of control over the learning process (Black et al., 2003), peer assessment has potential to counter these forces through involving students in the assessment process. There is however, also the danger that peer assessment can be perceived as a luxury or even somewhat irrelevant when performance in high-stakes examinations is what counts. 


\subsection{Prospects for peer assessment in Hong Kong}

In test-dominated settings such as Hong Kong, educational reforms promoting assessment change clash with well-established values; in the Chinese case, imperial civil service examinations dating back to the Han dynasty (Suen \& Yu, 2006). Peer assessment, as part of assessment reform, involves students in undertaking authentic and diverse assessment tasks, negotiating assessment criteria with teachers, participating in setting learning targets, and self-regulating their own learning (Morrison, 2003). Such reforms require substantive change in stakeholder beliefs and teacher expertise, and necessitate a re-conceptualization of the relationship of traditional external testing to the new assessment values (Morrison, 2003). Such change seemingly amounts to a significant shift in the assessment culture.

Nevertheless, there is nascent evidence that peer assessment has potential to act as a positive force in the Hong Kong context. Students from collectivist cultures, such as Chinese societies, are likely to devote more effort and perform better in peer co-operative processes (Salili, 1996) than those from more individualistic settings. Generalizing this point to peer assessment is as yet difficult to gauge because in Asian primary school classrooms, there is very little research into peer assessment. Carless (2005) examined how an English teacher in Hong Kong attempted to use peer assessment to promote learner independence and greater pupil participation in assessment; a finding relevant to the current paper was that pupils became more sensitive to grammatical errors and how to correct them.

Two relevant studies were carried out in the subject of English as a second language in Hong Kong secondary schools. It was found that students generally viewed assessment as the job of the teacher, who students considered to be more authoritative and the possessor of accurate knowledge; peers, in contrast, were viewed as lacking the language proficiency and expertise needed to give valid feedback (Sengupta, 1998). Similarly, Tsui and Ng (2000) found that Chinese students typically had more confidence in teacher comments which could provide specific explanations and concrete suggestions for revision. They did however, still believe that peers made contributions, including raising learners' awareness of their own strengths and weaknesses; and fostering autonomy in accepting or declining peer suggestions for revision. Although second language learners assess more proficiently in their native language (Oscarson, 1997), employing peers as assessors in second language classes 
may create an authentic audience, stimulate discussion in the target language, and motivate students to write and gain confidence (Mittan, 1989).

In sum, the framework for our analysis involves the interplay between research in Western settings on peer assessment and relevant factors in the Hong Kong socio-cultural setting. We seek to view the implementation of peer assessment through this socio-cultural lens in order to probe the possibilities and challenges in carrying out peer assessment in a test-dominated context.

\subsection{Research method}

This study employed a case study research design. Case studies probe the complexities of stakeholders' perceptions and actions in a specific context (Merriam, 1998) and yield insightful data when research is exploratory in nature (Yin, 2003). The research questions guiding the study were:

- How do students and teachers perceive peer assessment?

- What tensions and opportunities arise in the implementation of peer assessment?

The school case in this study arose from a wider funded project, which sought to document and stimulate the development of different formative assessment practices in English language classes in nine schools. This particular case was chosen because of the high English proficiency of students, which provided potential for them to peer assess in a second language, and teachers' enthusiasm in implementing peer assessment. Stimulating change was viewed as an aspect of the research process, rather than as contamination of data from a positivist viewpoint (Lincoln \& Guba, 2000) and hence receptivity of teachers to attempting new peer assessment strategies was an important selection criterion.

Two primary school teachers from an all-girls school participated. The two teachers were: Laurie, a native-speaker of Cantonese, the school's English Department Head; and Nancy, an expatriate native-speaker of English, who had implemented peer assessment in her home country. Initial baseline interviews lasting around 45 minutes were conducted with each teacher to ascertain their perspectives on general assessment issues in the school, and specific discussion of the rationale and processes of peer assessment. Eight classroom observations were carried out; three 
initial observations of peer assessment enabled us to form a view of early implementation. After analysis of this data, dialogues between the teachers and the researchers facilitated the development of adaptations for future implementation and these were explored through five further observations. Lesson observations focused mainly on how peer assessment was implemented and students' engagement with the process. Perceptions from teachers were collected through face-to-face and telephone interviews, supplemented by e-mail communications; these were carried out regularly over the two-year duration of the study.

The 34 Hong Kong Chinese student participants were members of a year 5 English language class in a school measured by standardized testing to be within the top $20 \%$ of Hong Kong primary schools. We followed this English class over the final two years of primary schooling during which students participated in a total of thirteen lessons centred on peer assessment activities. During observations, the researchers collected comments that students wrote on peer assessment worksheets, noted students' oral feedback to peers, and questioned individual students as they engaged with peer assessment. Additionally, three student focus group interviews with four students lasting around half an hour each time collected further student perspectives. Focus group interviews were undertaken because peer groupings encourage youths to talk more expansively (Bogdan \& Biklen, 1998). To encourage open dialogue, the mother tongue i.e. Cantonese was used during the focus group interviews which were translated into English by a bilingual research assistant.

All of the raw data were stored on an online database to facilitate ready access by the co-researchers. Interview transcripts, observation field notes and student focus group interviews were analyzed through the process of coding data, developing and revising inductive categories. Data were organized into themes for verification or revision, and the drawing of conclusions (Miles \& Huberman, 1994). Memberchecking (Creswell \& Miller, 2000) was carried out at the end of provisional data analysis by asking students and teachers questions designed to verify or disconfirm our interpretations of their perspectives and to seek clarification or elaboration, where necessary. As part of this process, concluding 45-minute interviews were conducted separately with each of the teachers.

In view of its exploratory nature, the research sought only to gauge teacher and student perceptions of the implementation of peer assessment. The study does not attempt to demonstrate whether peer assessment actually led to concrete improvement 
in student learning or performance. In other words, it does not examine whether the processes which were formative in intention actually did act formatively.

\subsection{Findings}

The findings are divided into five sub-sections reflecting the major themes uncovered in the data analysis. The first is essentially descriptive in outlining how peer assessment was implemented. The subsequent sections cover perceptions of how students engaged with peer assessment; the role of student language proficiency; the tension between repeated practice and possible boredom; and the impact of examinations at the end of primary schooling.

\subsection{How peer assessment was implemented}

Teachers in Hong Kong primary schools are specialists rather than generalists. Laurie and Nancy, both specialist English teachers, co-taught the class; in other words, both were present during lessons and shared teaching responsibilities. From the baseline interviews, they reported that their motivation for attempting peer assessment stemmed from their work in developing and implementing a school-based writing curriculum. Peer assessment, they explained, could complement and strengthen their attempts to improve their students' writing abilities. They did acknowledge however, that their colleagues had doubts about these goals, as Laurie commented:

"Our colleagues don't believe that students are able to do the peer assessments, especially when the more able students and the less able students sit together. How can the less able students mark the work of the more able ones?”

Our initial classroom observation revealed that the implementation of peer assessment went through various stages. First, students were introduced to the skills for peer assessment; the teachers used one lesson to guide students in assessing a piece of their own writing by using a self-assessment worksheet aligned with criteria derived from recently taught content. The following lesson focused on posters which students had developed. The criteria for assessing posters were introduced to students and included elements such as the impact of the poster, use of colour, imagination shown and relevance of illustrations. After the teachers had already graded the posters and identified the best work, the students used a worksheet to assess their peers’ work. 
The teachers explained to the students the marking criteria and benchmarks of good work. Our interview data revealed that the teachers' stated purpose of this exercise was to raise student awareness of using criteria to apply to marked samples. In this way, the students used peer assessment as a post-hoc reflection exercise that allowed them to compare their work to that produced by their peers. There was however, no opportunity to improve the work after receiving the feedback.

As the project aimed to promote change in practice, the researchers and teachers discussed this limitation and worked together to plan a way ahead. The teachers introduced a modified approach by explaining assessment criteria, asking the students to compare their peers' work against the criteria on their worksheets and then to revise their own work. Subsequently, students carried out several iterations of peer assessment as part of process writing. The basic format of worksheets was a list of criteria on the left-hand side of the page with smiley faces on the right-hand side and also spaces for peers to make suggestions. To support self-assessment following the peer feedback, the form included a checklist based on assessment targets and the prompt “I will improve my work by___. The students recorded targets for improvement, for example, "I will use more adjectives," "I will look for capital letters.” A space was dedicated for students to sign their names, indicating they had revised their work and corrected errors noted by their peers.

\subsection{Engagement or lip-service?}

By the time peer assessment as part of process writing had been adopted several times, focus group students reported a mix of positive and negative perceptions:

"I like the peer assessment form because it can make sure what we know and what we don’t know. I can correct things there”.

"I like the peer assessment because my grammar is very poor, if I get my peers to correct it, I can learn something”.

“My neighbor always ticks 'good' because she said the worksheet is very boring. Why? I think she always doesn't like to do the work”.

"I want my peers to be more serious writing the comments". 
It appeared that some students engaged themselves in the process and found it useful, whilst others became somewhat frustrated if they thought their partner was not supplying useful comments.

Students also referred to other aspects, for example, a student commented, "If the other person knows that you're wrong, you will write carefully next time. You don't want to be laughed at.” It seemed that knowing that others would read their compositions motivated some to take their writing seriously. For others, peer assessment instilled a sense of competition: "When I see there’s something wrong with others' work, I feel very happy because it means that I'm better than her.” This competitive element was also reinforced in focus group interviews, with students displaying a keen awareness of their language proficiency in comparison with peers.

Our classroom observations indicated that students frequently and sometimes at lightning speed ticked the "good" option for each criterion. Nancy commented, "I do feel that the girls may be just applying lip-service to it, in the sense that it is just another form to fill in, tick the boxes and get on with the next job.” The students also raised the concern that peers would tick a box without seriously considering the work. As one student commented, “She writes too easily 'very good'!” One student compared her peer comments with those from her teacher, "Ms. Nancy's comments are good. Because she is a teacher, her comments are different from our comments.” Another articulated a dilemma: "It's hard to write comments. If you write something bad, your classmate may be upset.”

In the focus group interviews, the students also observed that the comments they wrote could become formulaic: “For word choice, I’ll put, 'write more...' If their grammar was wrong, then you write, 'Please pay attention to your grammar'.” Laurie, however, perceived that the students had actually learned to generate feedback by modelling their comments on selected criteria: “At first they didn't know how to give the comments. Now they know how to refer to the form; they copy some of the phrases or wording from the form and then explain to the students what should improve."

The overall picture seemed to be that students perceived comments from peers as tending to be overly positive or simplistic. Issues of language proficiency, addressed in the next sub-section, exacerbated an observed tension between the engagement of some students and others only completing forms in a perfunctory 
manner. Competitive elements were also sometimes evident, perhaps because in testdominated settings students often evaluate their performance in relation to that of their peers.

\subsection{The role of student language proficiency}

A number of students commented on the impact of their language proficiency on how the peer assessment exercises were approached:

"If I have better classmates sitting next to me, I will really look at the comments very seriously, because she can give real comments.”

"If I have a partner, who has a lower English level, and I teach her but she doesn't know how to teach me, then I won't benefit.”

The general picture was that students' views on peer assessment varied depending on their own perceived language proficiency and that of their assigned peer assessor. Students who assessed work completed by peers of higher English proficiency expressed discomfort with the task because they could not identify errors or would simply assume that their more proficient peer was correct. High proficiency students found that their less proficient peers could not implement the feedback they offered and could not provide useful reciprocal comments.

The students in the focus group interviews suggested that most peers lacked the grammatical knowledge which could help students to improve their work. Nancy concurred with the students' concerns about language proficiency: “It comes back to knowledge. If you're not very good in tenses and you think it might be wrong, it might be hard to recognize an error.” During the final member-checking interview, Laurie expressed a belief that the students found peer assessment "interesting” as long as they received “a quality comment." However, if a student believed that her peer “can’t give her the quality comment and then she won't enjoy it.” A barrier to some students receiving useful and varied feedback was the seating arrangement. The homeroom teacher, not the English teachers, paired students at desks. Consequently, students tended to receive feedback from the same peer, regardless of language proficiency.

The observations in this section highlight challenges in applying peer assessment in second language classrooms. Language proficiency significantly 
affected students' ability to give and receive quality feedback. While some students saw value in looking at peers' work, perceptions of the quality of feedback determined their overall response to peer assessment. A further issue, explored in the next sub-section, is the dilemma of how teachers provide sufficient practice of peer assessment while avoiding an over-reliance on routine that may cause boredom.

\subsection{Routine and boredom}

During the second year of the study, students offered increasingly forthright opinions about the peer assessment tasks. One student expressed her feeling succinctly:

“The first time you feel, 'Ah, yes.' The second time, 'Oh, I understand a little bit.' The third time, 'I understand now.' The fourth time, 'It's boring.' The fifth time, 'I want to sleep.'”

Other students supported this view, suggesting that once they understood how to do peer assessment it became dull to them. Within the thirteen times peer assessment was carried out during the two-year period of the study, the teachers used peer assessment for varied types of writing, but the students commented that they became bored with routine. Nancy also acknowledged this:

"Like with any task, the first time you're not quite sure how to do it, the second time you can do it quite well. There's got to be a balance between allowing the students to practice enough so that they can do a good job and at the other extreme, gosh here comes another peer assessment again.”

There is a striking symmetry between this teacher comment and the previous quotation from a student.

In the focus group interviews, the students suggested various options to improve their peer assessment experience. There could be greater variety in the form's presentation by adding colour and illustrations, a possibility also noted by both teachers. However, one student stated, "Even if you change the form to a very colourful one and add a lot of cute cartoons, when you look at it for a long time, you will still be bored by it." Students noted that feedback could also be generated in 
alternative ways. Peers could assess easier tasks, but the teachers, who students considered more able to give useful feedback, could assess more challenging tasks. Also, pairing with different partners would facilitate receiving feedback from peers of both high and low ability. More variety, they suggested, would make peer assessment more interesting.

Nancy also reflected on whether peer assessment implementation needed some modification:

"I think we need to dress it up a bit. Maybe I tend to err on the side of competency rather than interest. That's an issue we need to look at, whether it means just designing the form differently or having some oral discussion rather than always completing a written form. Maybe even asking the girls 'what's another way we can do this?' We can empower them to help with that.”

Once it had become a routine, the processes of peer assessment needed some revitalization. As students reached the end of their primary schooling and were involved in preparations for commencing secondary education, interview data indicated new motivations for engaging in peer assessment as explored below.

\subsection{Preparation for secondary schooling}

Towards the end of the second year of the study, students began to prepare for important examinations at the conclusion of primary schooling. For preparation purposes, the teachers instructed students to review previous feedback from peers and their self-identified improvement targets recorded on the peer assessment forms in order to help them avoid making similar errors in the examinations. The students reported that this process of reviewing their improvement goals just prior to practice tests was helpful and extended their range of revision strategies beyond rote-learning and memorization. What had seemed boring now began to appear fruitful. Previous feedback could be used to anticipate challenges and discrete skills developed in assessing writing could be applied to self-assessment during the examination.

Laurie drew on practices developed in peer assessment to introduce examination-taking strategies. She put it as follows: "in the examinations, the students usually need to write introductions to stories or new endings, so I asked them to use the same habits to crosscheck their work. Although without any form to fill in, they 
can still circle mistakes.” In this way, examination preparation provided a new sense of purpose in engaging in peer assessment.

Some students also commented on the future transition to secondary schools, for example, "When you're in secondary schools, the teachers will not check things like this, so I think this is a good way to build our foundation.” Laurie offered a similar perspective: "We just want to motivate our students to learn from one another and at the same time we want them to have a habit of checking their own work. I want them to have the habit because I want to get them ready for secondary school.”

As students reached the end of primary schooling, Nancy also outlined some wider perspectives on the issues:

"It's about making the girls take some ownership and empowering them to improve themselves. In the end it's not just the teacher doing the red pen. It's teaching them to say, 'I can make it better and I can do that by myself'.”

Laurie expressed the view that at this stage, student development of the habit of peer assessment was even more important than whether or not students could do so effectively. She encouraged students "to invite others [e.g. parents, friends] to give comments on their assessment forms as well," and to "crosscheck each others' work even without any written reports.”

In summary, by the end of the study peer assessment seemed to be extended towards two wider goals: encouraging students to use the strategies they had learnt to prepare for examinations; and developing the dispositions suitable for secondary schooling.

\subsection{Discussion}

The main thrust of this small-scale study was to uncover student and teacher perceptions of peer assessment. In relation to the first research question, the findings indicate that students had some positive perspectives on peer assessment in terms of learning from each other and being encouraged to take responsibility for their own work. Peer assessment was less favoured when students were not able to receive useful feedback from their peers, and in this case they tended to prefer teacher feedback because it was more authoritative. Peer feedback was often considered inadequate because it was insufficiently critical or the partner lacked the requisite 
knowledge. The finding that students tend to value expert opinions more than those of novices is consistent with previous studies in Hong Kong (Sengupta, 1998; Tsui \& Ng, 2002) and in New Zealand (Peterson \& Irving, 2008). The teachers' perceptions of the classroom processes of implementing peer assessment were generally similar to those of students, in itself a finding worth highlighting. Teachers also viewed peer assessment as a useful component of a process approach to writing, and a wider skill that students needed in order to monitor their own work and become more empowered learners.

The second research question focused on tensions and opportunities arising from implementation of peer assessment. Probably the most critical tension related to the finding that whilst peer assessment is a skill that needs repetition and practice, after the students had carried out multiple iterations, they developed a sense of overfamiliarity. This resulted in boredom, a barrier also noted in Carless (2005), and confounded teachers' attempts to engage students in the manner they thought necessary to promote proficient peer assessment skills. Whilst the literature advocates sustained engagement with peer and self-assessment (Oscarson, 1997; Sadler, 1989), the way it was implemented in this study showed that there is a risk that students' interest will wane unless sufficient variety and challenge is introduced. More positively, peer assessment stimulates self-monitoring habits that might become increasingly important to students as their learning careers evolve. In this sense, a relatively short-term study, such as the current one, is unable to probe possible longerterm benefits of engagement with peer assessment.

These findings are roughly comparable to those found in other settings. A more striking contribution of the current study lies in its identification of a positive relationship between peer assessment and the goals of examination preparation and the transition to secondary schooling. Although students had expressed boredom with peer assessment, interest in the practice was revitalized towards the end of the study as students realized that it could help them prepare for examinations and the transition to secondary school education. Student involvement in assessment, focused on the development of skills to self-regulate performance, may be facilitated by drawing on the strong motivational force of examinations. In so doing, peer assessment may encourage examination preparation techniques which move beyond rote-learning and memorization. For instance, through peer assessment students learn to identify in 
advance the types of errors that they would be most likely to make in examinations and develop strategies to rectify them.

At the outset of the study, neither researchers nor teachers had anticipated that any explicit connection would be made between peer assessment and summative assessment. These connections emerged relatively late in the research process in response to the approach of high-stakes examinations at the end of primary schooling, and an awareness of the potential of peer and self-assessment for examination preparation. This finding suggests how peer assessment strategies can be adapted to suit the needs of a particular local setting and reinforces Kennedy et al.'s (2008) point that formative assessment cannot be treated in isolation from, or as an antidote to, the dominance of summative assessment. Following from this, a contribution of the study lies in indicating how a formative assessment strategy (in this case, peer assessment) is mediated and modified by interacting with the setting in which it is implemented. The development of such context-specific versions of formative assessment suitable for Asian settings merits further research. In particular, developing productive synergies between formative and summative assessment could be a potentially powerful strategy, especially in test-dominated settings.

\subsection{Conclusion}

By advocating formative assessment strategies such as peer assessment, Hong Kong's education authorities aim to stimulate a more balanced assessment culture and reduce the dominance of traditional one-off examinations. This paper has indicated some positive potential in implementing peer assessment in second language classrooms and also some tensions. One obvious way to support the practice of peer assessment would involve a whole-school approach in which collaborative forms of assessment are embedded in various subjects throughout the school. This would allow subjects taught through the mother tongue to reinforce the efforts of the second language teachers.

In test-dominated settings, integrating peer and self-assessment with the development of skills which can be profitably used in examinations seems to provide an opportunity for peer assessment to enter the mainstream, rather than remaining on the periphery of classroom practice. Using peer and self-assessment strategies to support future performance in summative assessment may be perceived as feasible by teachers and students given the prevailing socio-cultural beliefs. A challenge, 
however, is in cultivating links that would not introduce traits of high-stakes testing that are less appropriate for formative purposes, such as the use of assessment to compare students among each other, or training students through excessive repetition. To support this process, there is a need for further teacher development in assessment and the wider development of assessment literacy. This underscores the point that recommendations supporting formative assessment at the policy level need to be integrated and supported with continuous professional development at differentiated levels. Otherwise the common scenario of policy rhetoric having limited impact on the classroom is likely to reoccur.

For the wider Asian region, both the practice of peer assessment and research into it clearly need further investigation. Issues arising from this paper particularly in need of research are the following: What are the potentials and challenges of attempting to develop productive synergies between peer and self-assessment and examination preparation? If peer and self-assessment were seen as pathways to successful performance in examinations, would they then become a more central aspect of classroom practice in test-dominated settings? Studies of how peer or selfassessment might aid performance in high-stakes examinations (cf. McDonald \& Boud, 2003) would be particularly useful in supporting such developments.

\section{Acknowledgement}

This research is supported by the Research Grants Council of Hong Kong: HKU 7478/06H.

\section{References}

Adamson, B., \& Morris, P. (1998). Primary schooling in Hong Kong. In J. Moyles \& L. Hargreaves (Eds.), The primary curriculum: learning from international perspectives. London: Routledge.

Biggs, J. (1996) Testing: To educate or select? Education in Hong Kong at the crossroads. Hong Kong: Hong Kong Educational Publishing.

Black, P., Harrison, C., Lee, C., Marshall, B., \& Wiliam, D. (2003). Assessment for learning: Putting it into practice. Maidenhead: Open University Press.

Black, P. \& Wiliam, D. (1998). Assessment and classroom learning, Assessment in education, 5(1), 7-74.

Bogdan, R., \& Biklen, S. (1998). Qualitative research for education: An introduction 
to theory and methods. Needham Heights, MA: Allyn and Bacon.

Bransford, J. D., Brown, A. L., \& Cocking, R. R. (Eds.). (2000). How people learn: brain, mind, experience, and school. Washington, DC: National Academy Press.

Butler, D. \& Winne, P. (1995). Feedback and self-regulated learning: a theoretical synthesis. Review of Educational Research, 65(3), 245-281.

Carless, D. (2005). Prospects for implementation of assessment for learning. Assessment in Education, 12(1), 39-54.

Creswell, J. W., \& Miller, D. L. (2000). Determining validity in qualitative inquiry. Theory into Practice, 39(3), 124-130.

Curriculum Development Council (2001). Learning to learn: life-long learning and whole person development. Hong Kong: Curriculum Development Council.

Curriculum Development Council. (2004). English language education: English language curriculum guide (primary 1-6) Hong Kong: Curriculum Development Council.

Deakin-Crick, R., Sebba, J., Harlen, W., Yu, G., \& Lawson, H. (2005). Systematic review of research evidence of the impact on students of self- and peer assessment. London: EPPI Centre, Social Science Research Unit, Institute of Education, University of London.

Fredricks, J. A., Blumenfeld, P. C., \& Paris, A. H. (2004). School engagement: Potential of the concept, state of the evidence. Review of Educational Research, 74(1), 59-109.

Gardner, J. (Ed) (2006). Assessment and learning. London: Sage.

Kennedy, K. J., Chan, J. K. S., Fok, P. K., \& Yu, W. M. (2008). Forms of assessment and their potential for enhancing learning: Conceptual and cultural issues. Educational Research for Policy and Practice, 7(3), 197-207.

Kennedy, K.J. \& Lee, J.C.K. (2008). The changing role of schools in Asian societies: schools for the knowledge society. London: Routledge.

Lincoln, Y., \& Guba, E. (2000). Paradigmatic controversies, contradictions, and emerging confluences. In N. Denzin \& Y.Lincoln (Eds.), Handbook of qualitative research $2^{\text {nd }}$ edition. Thousand Oaks, CA: Sage.

McDonald, B., \& Boud, D. (2003). The impact of self-assessment on achievement: the effects of self-assessment training on performance in external examinations. Assessment in Education, 10(2), 209-220. 
McMillan, J. (Ed) (2007). Formative classroom assessment: Theory into practice. New York: Teachers college press.

Merriam, S. B. (1998). Qualitative research and case study applications in education. San Francisco, CA: Jossey-Bass.

Miles, M. B., \& Huberman, A. M. (1994). Qualitative Data Analysis: An Expanded Sourcebook. Thousand Oaks, CA: Sage.

Mittan, R. (1989). The peer review process: harnessing students' communicative power. In M. Johnson \& D. H. Roen (Eds.), Richness in writing: empowering ESL students (pp. 207-219). New York: Longman.

Morris, P. (2000). The commissioning and decommissioning of curriculum reforms-the career of the target oriented curriculum. In B. Adamson, T. Kwan \& K.K. Chan (Eds.), Changing the curriculum: the impact of reform on primary schooling in Hong Kong (pp. 21-40). Hong Kong: Hong Kong University Press.

Morris, P., \& Scott, I. (2003). Educational reform and policy implementation in Hong Kong. Journal of Education Policy, 18(1), 71.

Morrison, K. (2003). Complexity theory and curriculum reforms in Hong Kong. Pedagogy, Culture and Society, 11(2), 279-302.

Munns, G., \& Woodward, H. (2006). Student engagement and student self-assessment: the REAL framework. Assessment in Education, 13(2), 193 - 213.

OECD. (2005). Formative assessment: Improving learning in secondary classrooms. Paris: OECD.

Oscarson, M. (1997). Self-assessment of foreign and second language proficiency. In C. Clapham \& D. Carson (Eds.), Encyclopedia of language and education: language testing and assessment (Vol. 7, pp. 175-187).

Peterson, E. R., \& Irving, S. E. (2008). Secondary school students' conceptions of assessment and feedback. Learning and Instruction, 18(3), 238-250.

Poon, A. Y. K., \& Wong, Y. C. (2008). Education reform in Hong Kong: The "through-road" model and its societal consequences. International Review of Education, 54(1), 33-55.

Sadler, D. R. (1989). Formative assessment and the design of instructional systems. Instructional Science, 18(2), 119-144.

Salili, F. (1996). Accepting personal responsibility. In D. Watkins \& J. Biggs (Eds.), The Chinese learner: Cultural, psychological and contextual influences. 
Hong Kong: Comparative Education Research Centre and Australian Council for Educational Research.

Sengupta, S. (1998). Peer evaluation: I am not the teacher. English Language Teaching Journal, 52(1), 19-28.

Suen, H.K. \& Yu, L. (2006). Chronic consequences of high-stakes testing? Lessons from the Chinese civil service exam. Comparative Education Review, 50(1), 46-65.

Tierney, R. D. (2006). Changing practices: Influences on classroom assessment. Assessment in Education, 13(3), 239 - 264.

Tsui, A. B. M., \& Ng, M. (2000). Do Secondary L2 Writers Benefit from Peer Comments? Journal of Second Language Writing, 9(2), 147-170.

Walker, A. (2007). Leading authentically at the cross-roads of culture and context. Journal of Educational Change, 8(3), 257-273.

Yin, R. K. (2003). Case study research: Design and methods ( $3^{\text {rd }}$ edition). London: Sage Publications. 